\title{
Buscando el riesgo aceptable: sobre los métodos de análisis de riesgos empleados en la elaboración de políticas públicas
}

Roberto Losada Maestre*

Palabras clave: Riesgo, análisis de riesgo, marketing público, riesgo aceptable, percepción del riesgo, comunicación.

Every thing is sweetened by risk Alexander Smith (1830-1867), The Fear of Dying.

En la abundante literatura especializada sobre análisis de riesgos se encuentran cientos de obras, de carácter teórico, sobre el cálculo de probabilidades, el manejo de la incertidumbre con respecto a los datos de que se dispone, la incorporación de ésta a los procedimientos de toma de decisiones... Pero muy pocos autores se ocupan de las razones fundamentales que determinan, dan origen, o confieren valor, a los distintos métodos para el análisis de riesgos $^{1}$, las bases que han de fundamentar la opción adoptada a favor de uno u otro de esos métodos, las ideas rectoras que han de guiar el proceso de análisis, de medición y clasificación de los distintos riesgos, siguiendo principios que se han expuesto con profusión en la literatura sobre el asunto, pero en los que sólo en contadas ocasiones se detiene el analista de riesgos a pensar.

No se pretende aquí decir nada nuevo sobre el tema; se busca fundamentalmente acompañar al lector interesado -tanto si se trata de un lego en la materia como si, por el contrario, pertenece al floreciente negocio del riesgo- en un paseo por la enmarañada e intrincada senda de varios (los más relevantes) métodos empleados para medir los riesgos, para jerarquizarlos, para encontrar y definir, en último término, cuál de entre ellos es un riesgo aceptable, con la intención -tal vez no demasiado ambiciosa- de recalcar ideas y conceptos, fuera de todo lo cuantitativo y numérico, que permitan comprender cómo funcionan, por qué funcionan (si es que lo hacen), qué resultados se obtienen de la aplicación de esos distintos métodos y, sobre todo, apuntar alguna idea para suplir sus carencias.

* Profesor Ayudante de Ciencia Política y de la Administración en la Universidad Carlos III de Madrid. Estudio realizado en el marco del Proyecto I+D titulado "Estudio de los modelos de prevención, gestión y evaluación de catástrofes medioambientales en zonas costeras» (Vem 2003-2005), financiado por el Ministerio de Ciencia y Tecnología.

${ }^{1}$ Tal vez la obra más relevante que analiza distintos métodos para aproximarse al riesgo aceptable, siga siendo la de Fischhoff et al. (1981). 
Las teorías rara vez dan algo distinto a la comprobación del acierto o desacierto de las fórmulas que se imaginan como las más adecuadas al riesgo que se trata de analizar. Pero estas teorías han de surgir de un fondo intuitivo, de una apreciación subjetiva del fenómeno del riesgo, que tiene más que ver con la experiencia propia, la vida personal, el poso íntimo de vivencias que con la idoneidad o no de un cálculo de probabilidades.

El cálculo -los métodos cuantitativos de análisis de riesgos-acaba, por muy refinado que sea, siendo nada más que una herramienta que sirve para prever si los resultados no deseados de una determinada acción, que se considera arriesgada, pueden presentarse de tal manera que sean aceptados por aquéllos que han de padecer los efectos del empeño. No es más que la técnica operatoria que permite el paso de una concepción abstracta del esquivo término del riesgo a resultados numéricos y concretos sobre las posibles consecuencias de cada caso. El asombroso avance que las matemáticas probabilísticas han experimentado, desde que el caballero de Méré le pidiera a su amigo Pascal una técnica para ganar con facilidad a sus contrincantes en el juego de los dados, no puede dejar de sorprender. Pero esa misma sorpresa distrae la atención del aspecto ontológico del riesgo, que queda menospreciado. Todo analista de riesgos que descuide la atención debida a lo que cada individuo considera riesgo, a lo que sea para cada cual el riesgo, estará expuesto a graves fracasos: difícilmente podrá dar con el riesgo aceptable.

Para acertar a la hora de afirmar que determinado nivel de riesgo es aceptable -y aún para decidir si una técnica, una sustancia, una actividad, es o no arriesgada en absoluto-, es necesario meditar y conocer bien la razón de ser, las causas profundas que las convierten en arriesgadas, es decir, su aptitud para ser consideradas como tales por quienes habrán de recibir (o padecer) los efectos que se espera produzcan. Y se trata aquí de enfocar esta cuestión prescindiendo de todo lo accesorio, y en especial, de todo lo que represente una fórmula o un algoritmo que desemboquen en un determinado valor matemático; no se busca enjuiciar el acierto o idoneidad de aplicar la lógica bayesiana al análisis de riesgos, o si la utilización del método Monte Carlo es mejor que cualquiera otra técnica que quiera simular la incertidumbre con respecto a los datos de que se dispone para hacer el análisis. Se trata, por el contrario, de considerar el problema desde un punto de vista más general y cualitativo. Porque carece de sentido descender a la concreción cuantitativa sin la seguridad de tener bien entendida la idea de conjunto en sus acertados dominios. Sería erróneo inclinarse a favor de un determinado tipo de cálculo sin haber entrado a considerar primero si se necesita o no.

No resulta fácil encontrar en la literatura dedicada a estos temas, autores que planteen el problema como se pretende aquí, pero por eso mismo, puede que la reflexión que sigue en estas páginas sirva para iniciar una discusión que cubra el bache que se acusa.

\section{Sociedad del riesgo y riesgo aceptable}

Sin entrar a hacer averiguaciones respecto a la paternidad de la denominación de sociedad del riesgo ${ }^{2}$, no puede dejar de plantearse la pregunta de si resultará o no exagerada cuando lo que con ella se propone es caracterizar a la sociedad en que vivimos. Pareciera que con ella lo que se indica es que el fenómeno del riesgo no ha acompañado al hombre desde que comenzara a hollar las praderas de África hace más o menos un millón de años. Acordar salir a cazar un mamut para dar de comer a la tribu o aceptar el empleo de energía nuclear para producir electricidad, son decisiones que hacen referencia a unas actividades arriesgadas, como, por otro lado, lo es cualquier actividad cuyo resultado presente el menor grado de incertidumbre. Y toda acción humana se desarrolla en un escenario que tiene como fondo la incertidumbre. De modo que el riesgo es compañero inseparable de viaje del ser humano; un com-

\footnotetext{
${ }^{2}$ Lagadec (1981) ya empleaba el término «civilización del riesgo» mucho antes de que Beck (2001) hablara de la «sociedad del riesgo».
} 
pañero de viaje hacia el que se experimenta, no obstante, una decidida aversión, especialmente cuando su presencia puede suponer la pérdida de un bien estimado (sea éste la salud, el dinero, o un bello paisaje campestre).

¿Por qué se dice entonces que vivimos hoy en la sociedad del riesgo? Si no cabe afirmar en justicia que vivamos en una época más peligrosa que otras anteriores, sí se puede afirmar que los riesgos a los que hoy nos enfrenamos son distintos a los de esos períodos pretéritos. En nuestra sociedad actual, los avances tecnológicos han generado riesgos de una escala no conocida hasta ahora (piénsese en la energía nuclear, en las innumerables sustancias químicas capaces de destruir la vida, etc.), que no son riesgos secundarios, o riesgos no deseados del progreso, sino que son el progreso mismo. A eso se suma que no hay un área de la vida que esté exenta de riesgos: nuestras finanzas se ven amenazadas por decisiones que grandes empresas toman al otro lado de los océanos, los matrimonios no son un refugio contra el riesgo, no hay seguridad en la calle, ni en el trabajo, ni en el sexo.

Puede decirse esto mismo con otras palabras: el riesgo, hoy, ha perdido su dimensión humana. El mundo en el que podíamos confiar, el de la causalidad simple, el de la promesa baconiana ${ }^{3}$, en el que había un claro lazo de unión entre las acciones del hombre y los resultados de las mismas, en el que la escala de los acontecimientos era una escala humana, ha desaparecido para siempre. Estamos en la «modernidad reflexiva» de Beck (2001), en la que los riesgos producen efectos que se escapan a nuestro control, son capaces de destruirnos y sobre los que apenas conocemos nada. Además, son riesgos producidos por nosotros mismos. No es la naturaleza la que puede generar las más horribles de las catástrofes, el riesgo no es externo, sino fabricado por los propios hombres, manufactured risk lo llama Giddens $(1998)^{4}$.

Es el sentimiento de inseguridad lo que caracteriza el paso de la vieja sociedad industrial a la moderna sociedad reflexiva, del riesgo. El resultado de la búsqueda de la nueva seguridad puede dar lugar a dos respuestas: una, el regreso al orden tradicional, a las viejas instituciones que nos protegían, como el Estado, la nación y la cultura, pero sólo serán fachadas que pretenden ocultar el mundo cambiante que transcurre por debajo. La segunda respuesta es la que puede dar una nueva política para la sociedad del riesgo.

Esa política requiere unas nuevas relaciones entre el público, los expertos y los políticos. Exige un respeto y un diálogo que llene el hueco de la desaparecida fe ciega en la capacidad de tomar decisiones acertadas que ha caracterizado a la política hasta ahora. Exige, como se verá más adelante, generar confianza.

En esta nueva sociedad, en esta modernidad reflexiva, los fundamentos sobre los que se apoyaba la justificación de la existencia misma del Estado, parecen haberse desplazado: ya no son la creación de riqueza y de seguridad

${ }^{3}$ El intento de controlar y dominar la naturaleza a través de la ciencia no ha sido un éxito. Abandonamos el viejo concepto de una ciencia que nos enseñaba cómo era el mundo, que nos mostraba como vivir en armonía con él, por la promesa de un progreso ilimitado a través del conocimiento científico. «El espíritu baconiano cambió profundamente la naturaleza y el propósito de la investigación científica. Desde el tiempo de los antiguos, los objetivos de la ciencia habían sido la sabiduría, comprender el orden natural y vivir en armonía con él. En el siglo XVII esta actitud cambió a su polo opuesto, de la integración a la autoafirmación. Desde Bacon, el objetivo de la ciencia ha sido el conocimiento que puede usarse para dominar y controlar la naturaleza» (Capra 1983: 21).

${ }^{4} \mathrm{Ni}$ siquiera los recursos nacionales parecen ser suficientes para enfrentarse a esta nueva situación, «las naciones no pueden enfrentarse con eficacia al riesgo internacional (...), con la división global del trabajo, con la polución atmosférica» (Boyne 2003: 99). Junto a ello, no hay que olvidar que, como dice Carl Sunstein, se trata de un fenómeno universal: «Por todo el mundo, las naciones tratan de reducir los riesgos, mejorar la seguridad y prolongar la vida. De hecho, la reducción del riesgo se ha convertido en el principal objetivo de los gobiernos modernos. ¿Qué habría que hacer respecto al calentamiento global? ¿Cómo pueden las naciones manejar los riesgos relacionados con el terrorismo, incluyendo los riesgos relacionados con las armas químicas y la seguridad en los aviones? ¿Deberían los gobiernos regular o prohibir la manipulación genética de los alimentos? ¿Debería eliminarse el arsénico del agua potable? ¿Cuál es la relación entre la política energética y la protección medioambiental? ¿¿Deberían los gobiernos obligar a que los automóviles cumplan ciertos estándares de ahorro de combustible? ¿Podrían esos estándares hacer que los coches fueran menos seguros? Preguntas de este tipo preocupan a las instituciones públicas, no sólo a nivel nacional, sino también internacionalmente» (Sunstein 2002: viii). 
entendida en un sentido restringido; «ese desplazamiento ha convertido la evitación de los peligros que surgen del propio desarrollo tecnológico y económico de la sociedad, no sólo en una de las responsabilidades del gobierno, sino en su ocupación principal»(Woollacott 1998: 47) .

El objetivo final de la política con relación a estos nuevos riesgos es encontrar el nivel de «riesgo aceptable». No puede contemplarse como posibilidad el dejarse llevar por la deriva apocalíptica; es necesario abandonar el imperativo de la abstención total ante el riesgo si se quiere disfrutar de los beneficios que ofrece una tecnología compleja y caracterizada por relaciones estrechas e inesperadas entre sus componentes (Perrow 1999). Un principio de precaución ${ }^{6}$ estricto implicaría que la respuesta a la pregunta sobre cuándo puede estar justificada la asunción de un riesgo sea "nunca». La aplicación general de la idea del «riesgo cero» es imposible, puesto que exigiría una dedicación ingente de recursos y la renuncia a indudables ventajas del progreso tecnológico.

Al encargado de tomar las decisiones, de elaborar las políticas públicas, le queda, por tanto, la nada envidiable tarea de dedicarse a la gestión de riesgos. Cuando el futuro ofrece un rostro cada vez más amenazante, la esfera privada de creación de riesgos ya no puede ser considerada apolítica. "De hecho, un espacio completo de subpolitica híbrida surge en el terreno de las decisiones sobre inversión, desarrollo de productos, gestión de plantas y prioridades de investigación científica» (Beck 1998: 10).

Transfórmase la política en una tarea de predicción que se encarga ahora, no de repartir los beneficios, sino los daños; que ha de satisfacer las demandas de minimización o eliminación del riesgo futuro, o establecer las compensaciones oportunas para reparar esos daños. Y si la tarea de predicción pudiera parecer poca cosa, hay que tener siempre presente el hecho de que sobre los distintos riesgos, sus orígenes y sus consecuencias, hay diferentes puntos de vista enfrentados; los expertos no se ponen de acuerdo, diversos análisis científicos que sostienen visiones encontradas son esgrimidos como argumentos por quienes se ven afectados por los riesgos, positiva o negativamente, en un enfrentamiento en el que todos parecen estar del lado de la verdad. Y no es tarea de la ciencia, ni está capacitada para ello, afirmar cuál es el riesgo aceptable y cuál no lo es.

Gira, por tanto, la política del riesgo en torno al problema de qué es el riesgo aceptable ${ }^{8}$. La respuesta no es sencilla, pero encontrarla facilita las cosas a los actores que están implicados en la gestión del riesgo:

- Para los políticos es una guía que facilita la toma de decisiones.

- Para los expertos es una ayuda a la gestión y la investigación.

- A los ciudadanos o afectados les facilita la evaluación de la forma en que se está protegiendo su bienestar 0 sus intereses.

Puede afirmarse, al modo en que lo hacen Derby y Keeney (1981), que el riesgo aceptable es el riesgo asociado a la mejor de las alternativas presentadas, es decir, aquéllas que están a nuestro alcance, y no con aquélla que sería la mejor pero que no está disponible. Para estos mismos autores, responder a la pregunta de qué sea el riesgo

5 Todas las citas han sido traducidas por el autor.

${ }^{6}$ La precaución está íntimamente ligada a la idea de los riesgos irreversibles que, dice Olivier Godard (2002: 73), viene de Alemania, donde durante los años 70 va afirmándose bajo el nombre de Vorsorgeprinzip o, literalmente, principio de la previsión, destinado a guiar las políticas de lucha contra la contaminación.

7 «La precaución aspiraría idealmente a un nivel de riesgo cero, o a la inexistencia de probabilidades de efectos nocivos, con independencia de los costes económicos de tal actuación, tanto si se plasma en una política de no autorización de determinadas tecnologías como en una política de protección «total» de la salud pública» (Aguilar 2003: 67-68).

${ }^{8}$ Los economistas prefieren hablar de riesgo óptimo y no de riesgo aceptable. Para ellos el nivel óptimo de riesgo se encuentra en el punto donde el coste de reducir el riesgo y las pérdidas esperadas caso de producirse el evento negativo alcanzan un mínimo. 
aceptable implica seguir cinco pasos: (1) definir las alternativas, (2) especificar los objetivos que quieren alcanzarse, (3) identificar las posibles consecuencias de cada alternativa, (4) cuantificar las consecuencias y (5) analizar las alternativas para escoger, de entre ellas, la mejor. Sin embargo, no son pasos sencillos, ellos mismos reconocen que «determinar el riesgo aceptable depende de muchos factores que pueden cambiar con el tiempo debido a nuevas tecnologías y experiencias y puede diferir de una persona o grupo a otro» (Derby y Keeney 1981: 221).

No le vale ya a quien ha de tomar la decisión sobre qué riesgo merece la pena y cuál ha de ser descartado considerar el fenómeno como objetivo, que puede ser medido y analizado con la tecnología adecuada y que, por tanto puede ser gestionado. Ha de tener en cuenta el riesgo como un fenómeno subjetivo, que se construye socialmente?

En su ayuda vendrán los distintos métodos ideados para establecer listas ordinales en las que ubicar los riesgos, métodos de análisis y evaluación para los fenómenos arriesgados con los que conviven las sociedades actuales. Pero sería vano el empeño de quien pretendiese dar con la respuesta más atinada, sin haber asimilado antes, y hasta la médula de sus huesos, los principios e ideas que rigen cada uno de los métodos; tan vano como el de un arquitecto que quisiera construir una edificación duradera sin conocer los fenómenos de tensión subyacentes en la estructura. Los párrafos que siguen se dedican a desbrozar ese camino.

\section{El análisis de riesgos}

Todo método de análisis de riesgos tiene una finalidad con unas condiciones esenciales, y otras accesorias, que cumplir y se tienen, claro está, unos medios para llevarlo a cabo.

La finalidad varía enormemente de un caso a otro, pero siempre existe. La realización del análisis resulta demasiado costosa como para servir de simple entretenimiento a los hombres de esta época, igual que le ocurría a los de épocas pasadas. Cuando se lleva a cabo el análisis de un riesgo se hace por algo. Tal vez no siempre se alcance, pero se analiza para algo. Esto quiere decir que el análisis tiene una función que va más allá de sí mismo; tiene alguna otra finalidad o función que lleva, como consecuencia esencial, el que el riesgo analizado aparezca con una forma definida y estable en el tiempo, que el riesgo sea algo manejable. Pero no es la finalidad única, ni siquiera la primaria del análisis. te forma:

Para lo que aquí nos interesa, las finalidades funcionales primarias pueden quedar establecidas en la siguien-

1. a Singularizar un determinado riesgo. Distínguese el riesgo de los demás similares a él; es aislado, cercado, defendido del resto de riesgos que pretenden confundirse con él. Se establecen de manera clara y distinta sus límites, el lugar donde acaba y comienzan los demás.

2. ${ }^{a}$ Ubicar el riesgo en una determinada posición en relación con los demás. Es decir, establecer si el riesgo analizado es de mayor o menor consideración, si exige una atención urgente o no, en comparación con otros riesgos también analizados.

3. ${ }^{2}$ Establecer el riesgo aceptable. Se decide cuáles son los riesgos que se correrán y cuáles, por el contrario, por considerarse inaceptables, no serán asumidos.

\footnotetext{
${ }^{9}$ Es Zinn quien muy acertadamente realiza esta distinción (Zinn 2005).
} 
Aparte de estas finalidades, existen otras de menor generalidad -como puede ser el establecer límites de exposición a sustancias, números determinados de horas de trabajo en cierto ambiente, especificar condiciones de fabricación, instrumental o vestuario a emplear en determinadas actividades, etc.-, y que no son fáciles de clasificar de una manera más rígida ni parece oportuno el hacerlo ahora mismo.

Las finalidades funcionales primarias, van siempre acompañadas de otras, más o menos obligatorias o necesarias, que determinan infinidad de variaciones, y que dan personalidad a cada caso concreto.

Así, por ejemplo, la dosis máxima de exposición a una determinada sustancia puede quedar establecida en un nivel cuando se trata de un componente que no habrá de ser ingerido; si se trata de emplear esa misma sustancia, de manera directa o indirecta -a través, por ejemplo, de la alimentación del ganado-, en la fabricación de productos para el consumo humano, la dosis tolerable variará casi con toda seguridad. Los límites de velocidad establecidos para los vehículos automotrices no serán los mismos dependiendo tanto del tipo de vehículo como de la superficie por la que se espera que se desplace, y así podrían multiplicarse los ejemplos.

Existen pues, unas condiciones imprescriptibles que ha de cumplir el análisis, otras serán puramente accesorias o de conveniencia, y habrá otras intermedias que sean necesarias cualitativamente pero que admiten, en lo cuantitativo, un margen mayor o menor. Un análisis podría decirnos que la producción nuclear de energía entraña riesgos, pero nadie admitiría tan escueta respuesta como resultado válido del análisis; sin embargo, una ponderación de esos riesgos frente a los beneficios que presenta la energía nuclear y los riesgos que suponen otras opciones energéticas es perfectamente válida, sin que el análisis deba forzar a adoptar una u otra, pues ésta no es decisión del analista, sino del encargado de definir la política pública energética. Hasta dónde se acepta la elasticidad del método escogido es punto difícil de concretar y está sujeto a opiniones puramente subjetivas.

En estos casos hay que llegar a un compromiso con las posibilidades técnicas, económicas y otras que se irán comentando ${ }^{10}$.

Pero, en cualquier caso, debe subrayarse la gran importancia que tiene el fijar, en cada caso, la finalidad y las características del análisis propuesto, diferenciando en él lo esencial de lo conveniente y de lo simplemente accesorio.

Pasando a otro aspecto: de todos es sabido, que el análisis tiene siempre unas condiciones o limitaciones de tipo económico. A igualdad de las demás condiciones, es preferible que el análisis sea lo más económico posible.

Por supuesto, puede dedicarse una desproporcionada cantidad de dinero a analizar una actividad que se considera, o sospecha, arriesgada. La razón de ello puede ser difícil de enjuiciar: justificar la adopción de una determinada política, favorecer los intereses de determinado sector, tranquilizar a un sector de la población... El problema, a este respecto, está en marcar unos justos límites, que variarán considerablemente de un caso a otro. Sea

${ }^{10}$ Ello sin olvidar que mejores mediciones abren más posibilidades, más investigación trae a la luz del día un nivel mayor de desconocimiento. Así, el informe del National Research Council de Estados Unidos, Risk assessment in the Federal Government: managing the process, con respecto a las sustancias químicas. afirma que se conocen más de 5 millones de sustancias químicas diferentes. De éstas, menos de 30 han sido definitivamente ligadas al desarrollo del cáncer en los humanos, 1500 han sido relacionadas con el cáncer en animales y alrededor de 7000 han sido testadas en total con respecto al cáncer. Ello viene a reflejar el nivel de desconocimiento existente (citado en Adams 1995: 45). En el mismo sentido se pronuncian Douglas y Wildavsky (1982: 53), dando las siguientes cifras con respecto al mismo problema y añadiendo la dificultad de superarlo: «(...) Un impresionante número de sustancias químicas sintéticas han sido creadas, muchas mejoran la vida pero otras son causa de preocupación. Hoy hay cerca de 4,5 millones de sustancias químicas conocidas, con talvez 45000 usadas comercialmente. 'Se necesita un equipo de científicos' nos dice Costle (director de la EPA), 300 ratones, de 2 a 3 años y cerca de 300000 dólares para determinar si una única sustancia química sospechosa causa cáncer». 
como fuere, aparte de algunos excepcionales y aún en ellos, existen siempre unos límites de carestía que marcan hasta dónde el análisis es realizable o no. Y, en general, puede decirse que, a igualdad de efectos, la condición de mínimo coste es siempre válida y debe atenderse.

La solución, sin embargo, no se ofrece nunca de forma clara y determinada; se traduce en un aumento o disminución de la frabilidad de los resultados, de su aplicabilidad, de los objetivos que se persiguen, de su capacidad para convencer, etc. Y si la variable costo es definible numéricamente, las ventajas o inconvenientes que ella implica, en órdenes tan diversos, son con frecuencia, imposibles de valorar cuantitativamente. Por ello, el enjuiciamiento, necesariamente subjetivo de la cuestión, da lugar a discusiones y opiniones encontradas: discútese si una mayor dedicación de recursos no hubiera ofrecido resultados distintos - bien a favor, bien en contra- con respecto al riesgo que supone la actividad cuestionada; se plantea la posibilidad de que unos recursos considerados abundantes pudieran haber sido destinados al análisis de otros riesgos que aparecen como más perentorios; se cuestiona el gasto cuando los recursos proceden de una fuente con intereses directos en el resultado... (Ver Tabla 1).

\section{TABLA 1}

Razones a favor y en contra de realizar análisis de riesgos más complejos y sofisticados.

\begin{tabular}{|c|c|}
\hline \multicolumn{2}{|c|}{ Análisis más complejo y sofisticado } \\
\hline Razones para realizarlo & Razones para no realizarlo \\
\hline Los costes de las actividades alternativas son mayores que los del análisis & Los costes del análisis superan el de las actividades alternativas \\
\hline Evitar consecuencias gravosas de un mal análisis & Admitir la falta de conocimientos respecto al objeto de análisis \\
\hline $\begin{array}{l}\text { Ofrecer un análisis comparativo de los impactos en los distintos grupos } \\
\text { de afectados }\end{array}$ & Reconocer la certeza de los efectos negativos \\
\hline $\begin{array}{l}\text { Permitir la consideración en el análisis de la incertidumbre respecto a los } \\
\text { datos (imput) y su influencia en los resultados obtenidos en el análisis (output) }\end{array}$ & $\begin{array}{l}\text { Reconocer que la excesiva incertidumbre impide obtener conclusiones } \\
\text { con pretensiones de validez }\end{array}$ \\
\hline $\begin{array}{l}\text { Favorecer el desarrollo y la mejora de los métodos de análisis para } \\
\text { investigaciones futuras }\end{array}$ & $\begin{array}{l}\text { Reconocer la falta de interés por parte de quien ha de adoptar las } \\
\text { decisiones }\end{array}$ \\
\hline $\begin{array}{l}\text { La existencia de un amplio acuerdo social en cuanto a la calificación de la } \\
\text { actividad como arriesgada }\end{array}$ & $\begin{array}{l}\text { Ausencia de acuerdo a nivel científico respecto a la consideración de la } \\
\text { actividad como arriesgada }\end{array}$ \\
\hline $\begin{array}{l}\text { Consideración de las consecuencias de un mal análisis como catastróficas } \\
\text { y afectando a generaciones futuras }\end{array}$ & Escasa atención recibida por los medios de comunicación \\
\hline Disponer de tiempo para la obtención de resultados & Necesidad de adoptar medidas de urgencia \\
\hline
\end{tabular}

Fuente: Elaboración propia a partir de Cullen y Small (2004).

Por otra parte, el costo ha de mirarse en relación con los beneficios, directos o indirectos, ponderables o no, que se esperan del análisis (como puede ser la prevención de muertes en un futuro aún lejano). El analista, consciente de su misión en el seno de la sociedad que lo rodea, debe pensar también que conviene, pues, enfocar el tema presupuestario desde más lejos, con caracteres de generalidad, y meditar en las enormes consecuencias que traen consigo estos problemas. El que las técnicas de análisis estén más o menos avanzadas, más o menos adaptadas a las características de la sociedad en que se aplican, puede dar lugar a que, en el conjunto de la economía nacional y del bienestar social, se produzcan mejoras notables o terribles pérdidas que pueden representar fácilmente cientos de millones. 
Unido o en pugna con la condición económica, se presenta el problema temporal. Todo análisis de riesgos tiene un ritmo de ejecución que está relacionado con su dificultad, la disponibilidad de datos, la técnica empleada, el presupuesto invertido, etc. Pero hay que tener en cuenta la posible existencia de toda una serie de razones que pueden aconsejar la alteración de ese ritmo, e incluso a consecuencia de ello, puede llegar a cambiarse el tipo de análisis a realizar.

La dependencia de una consignación presupuestaria anual fija, puede obligar a ralentizar la marcha del análisis para evitar el encarecimiento y la dificultad que representa el adelanto de dinero a préstamo. Por el contrario, los intereses de los capitales que pueden quedar inmovilizados a la espera de un resultado, de una decisión respecto a la aceptabilidad o no de determinado riesgo y, aún más, el quebranto económico y social que representa el retrasar los beneficios que dicha actividad haya de producir una vez puesta en marcha, pueden justificar una aceleración del proceso así como un aumento del gasto.

De todo este conjunto de consideraciones y factores tan heterogéneos, ha de salir el planteamiento del problema que trata de resolver el analista: qué método de análisis de riesgo emplear en la búsqueda del deseado riesgo aceptable.

La idea misma de riesgo aceptable ${ }^{11}$ es esencial, por cuanto, de no ser el objetivo del método del análisis empleado se escaparía de la intención que anima la elaboración de estas páginas; aunque ha de tenerse presente que no tiene que ser necesariamente la razón única y primordial del análisis. Sin embargo, interesa destacarla, por cuanto es aquélla la que define el tema a tratar a continuación y que puede quedar planteado de la siguiente manera: «De cómo elegir el método de análisis de riesgos que, dentro de las condiciones que impone su finalidad, resulte el más adecuado y económico para llevarlo a cabo con los datos y las técnicas de que se dispone».

Queda claro, pues, que estamos planteando un problema de metadecisión ${ }^{12}$. No se trata tanto de decidir sobre el riesgo que se aceptará correr, como de decidir cómo se decidirá.

Cuando el riesgo mantenía una escala humana, cuando no estaba originado fundamentalmente por la complejidad de los sistemas, no era frecuente, si es que se daba en algún caso, separar la idea de riesgo de la idea de análisis del mismo ${ }^{13}$. Hoy, esta distinción total es corriente y necesaria y, por ello, hay motivo para ocuparse del análisis en sí y de la relación que tiene con el riesgo a ser analizado. Esta relación, es decir, la adecuación del método al riesgo, requerirá, por tanto una atención especial; pero sin olvidar el resto de condiciones que entran en el problema de la elección. Porque, precisamente, el menospreciar el resto, el pensar sólo en la idoneidad del método de análisis es un defecto corriente del profesional, del técnico; del mismo modo que lo es, frecuentemente, por parte del lego o del político, menospreciar esa relación a favor de otras consideraciones como el miedo, la búsqueda de réditos políticos, etc.

En definitiva, la elección debe haber tenido presente estas cuatro cosas: los datos materiales de que se dispone para realizar el análisis, el tipo de riesgo que se trata de analizar, el propósito que se persigue con el análisis y los

${ }^{11}$ Esta idea ha sido puesta en cuestión por varios autores. Véase más adelante.

12 «La gestión del riesgo no tiene un «manual» que resuma una amplia experiencia de ensayo y error en un conjunto de reglas para la toma de decisiones. Como resultado, puede haber tantos métodos para tomar decisiones sobre riesgos aceptables como encargados de tomar esas decisiones» (Fischhoff et al. 1981: 47).

${ }_{13}$ Para unos hombres que consideraban que el resultado de sus acciones dependía de la buena voluntad de un grupo más o menos amplio de seres divinos, la idea de realizar un análisis de riesgos había de parecerles forzosamente absurda. «La genuflexión ante los vientos era la única forma de gestión del riesgo que captaba su atención (de los griegos): sus poetas y dramaturgos cantaban repetidamente su dependencia de los vientos y sacrificábanse los hijos bienamados para apaciguarlos» (Bernstein 1998: 16). 
recursos con los que se cuenta ${ }^{14}$. Pueden esquematizarse las condiciones que afectan la elección del método de análisis para la búsqueda del riesgo aceptable como queda reflejado en la Tabla 2.

\section{TABLA 2}

\section{Ecuaciones, y sus correspondientes variables, a las que ha de dar respuesta el análisis de riesgos}

\begin{tabular}{|l|l|}
\hline Ecuación & Variable \\
\hline procedimiento & datos \\
\hline objetivo & finalidad \\
\hline presentación & nivel de seguridad \\
\hline condiciones económicas & recursos \\
\hline
\end{tabular}

Fuente: Elaboración propia.

Por supuesto, el modelo puede complicarse aún más si se quieren reflejar también las mutuas exigencias e influencias que ejercen unas variables sobre las otras. Todas ellas hacen el sistema incompleto, en el sentido de que no es posible resolver todas las ecuaciones plenamente o en todo el grado que sería de desear: ni se dispondrá de todos los datos ${ }^{15}$, ni existirá una finalidad exclusiva, ni se alcanzará un nivel de seguridad absoluto, ni se podrá acudir a un expediente de gasto ilimitado. Obligado resulta entonces conformarse con resolver el problema aproximadamente, limitando al mínimo los inconvenientes y sacrificando cuanto sea considerado como menos importante. Solamente puede pretenderse que el sistema se complete con el mínimo error, y esto ya no es poco.

En el centro de cada una de estas ecuaciones o, a trueque de no salirnos de la comparación matemática podríamos decir que en la solución de cada una de ellas, se encuentra uno de los actores que intervienen en la definición del riesgo como aceptable, conforme queda reflejado en la Tabla 3. Las herramientas del analista, del científico, son los datos; habrá de encargarse de recopilar los necesarios, será garante de su frabilidad y habrá de llevar a cabo la parte técnica del análisis. El objetivo a conseguir y que desencadena el proceso está en manos de quienes son responsables de la seguridad, de la gestión de los riesgos, de salvarnos de los daños que la complejidad actual exige como pago por los beneficios que reporta: los decisores públicos, los políticos. El ciudadano se inquieta por su salud y la de su familia, por su seguridad económica, por su estilo de vida; si el riesgo es aceptable, lo es para él fundamentalmente. Los recursos destinados a la averiguación del riesgo aceptable pueden provenir del gasto público, pero es lógico pensar que buena parte de los análisis vendrán financiados por quienes tienen un interés directo en la realización -o prohibición- de la actividad considerada arriesgada.

No es esta clasificación rígida y, al igual que se ha señalado previamente al hablar de las variables, las relaciones entre los distintos actores no son lineales y sencillas. Así, por ejemplo, está el político en una situación difícil:

14 Fischhoff et al. (1981: 54) establecen siete criterios para evaluar la aceptabilidad (la idoneidad, pudiéramos decir) del método -»aproximación» lo llaman ellos- empleado para resolver la pregunta de qué riesgo es aceptable: debe ser completo, lógico, práctico, abierto a evaluación, políticamente aceptable, compatible con las instituciones y debe facilitar el aprendizaje. Todos ellos caben en la clasificación propuesta aquí, con la ventaja de que ésta se ajusta a las incógnitas a las que debe dar algún tipo de respuesta el analista: ¿̨con qué datos se cuenta?, ¿¿de qué técnica se dispone?, ¿qué finalidad se persigue? y ¿con qué recursos se cuenta?

15 Vana ilusión es pretender dominar toda la información que hace al caso cuando de analizar un riesgo se trata, pero no es sólo una cuestión de cantidad, sino que entra en juego también la incertidumbre con respecto a los datos que se poseen y la manera en que una variación en los mismos genera variaciones en los resultados. 
si se advierte, tras un análisis científico, que determinada actividad entraña riesgos hasta el momento no considerados o desconocidos, inmediatamente, grupos de interés apoyan estos resultados o inician investigaciones -con la misma validez científica que las anteriores- encaminadas a mostrar lo inocuo de la actividad, en los medios de comunicación se recoge el enfrentamiento de posturas y se encuentra el ciudadano alarmado por la falta de certezas, su natural aversión al riesgo le lleva a demandar del político medidas que incrementen la sensación de seguridad, se ven obligados los políticos a incrementar los estándares, las medidas de prevención, pero este incremento no encuentra justificación en los análisis anteriores: se exigen nuevos análisis y se reinicia el proceso -de desconfianza-, tal y como se muestra en la Figura $1^{16}$.

\section{TABLA 3}

Ecuaciones, variables y actores que forman parte del análisis de riesgos

\begin{tabular}{|l|l|l|}
\hline Ecuación & Variable & Actor \\
\hline procedimiento & datos & analista \\
\hline objetivo & finalidad & político \\
\hline presentación & nivel de seguridad & ciudadano \\
\hline condiciones económicas & recursos & grupos de interés \\
\hline
\end{tabular}

Fuente: Elaboración propia.

\section{FIGURA 1}

\section{El círculo vicioso de la falta de confianza en politicas públicas sobre riesgos}

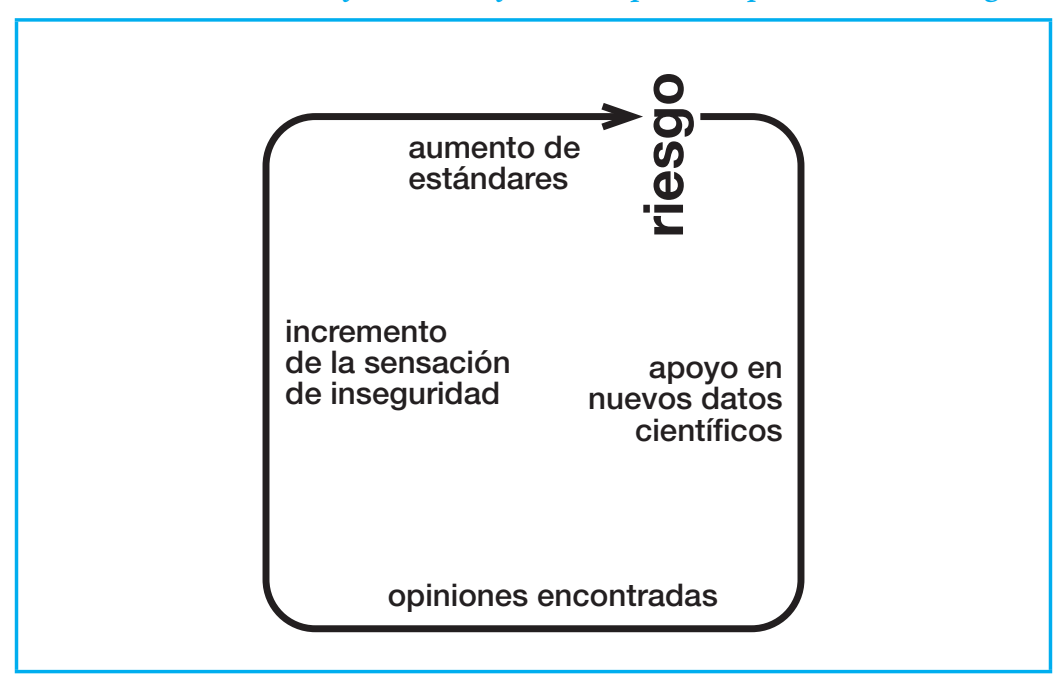

Fuente: Elaboración propia.

Debe la política dar forma institucional a la relación crítica que hoy se tiene con la ciencia. La falta de una base cierta sobre la que argumentar hace que la mayor parte de las discusiones en torno a los riesgos se centren en si

${ }^{16}$ La reacción a esto es profundizar aún más en los análisis para buscar mayores evidencias. El problema entonces es que la incertidumbre se incrementa en la misma medida en que desciende la severidad de las consecuencias analizadas, debido a que los datos se hacen cada vez menos fiables. Mejores mediciones abren más posibilidades, más investigación trae a la luz del día un nivel mayor de desconocimiento. 
éstos existen o no. A los políticos se les genera, entonces, un problema: si aceptan que el riesgo existe -y diseñan políticas destinadas a reducirlo e incluso a eliminarlo- no se verán sus efectos negativos y podrían ser acusados de alarmistas, de frenar el desarrollo y el progreso. Si deciden que el riesgo no existe, o que los beneficios compensan sobradamente los efectos negativos del mismo, diseñarán una política permisiva que tratarán de fundamentar en las opiniones de los científicos, pero si, finalmente, se manifiestan los efectos negativos que se esperaban, serán acusados de encubridores. La situación no es fácil. «En la sociedad del riesgo hay un nuevo clima moral en la política, marcado por un tira y afloja entre acusaciones de alarmismo por un lado y encubridores por otro» (Giddens 1998: 29).

Estriba la dificultad, pues, en la divergencia existente entre la realidad de la ciencia y la tarea encomendada al gobierno, porque se considera siempre posible y, por ello, obligatorio, establecer una regulación segura de cuantas amenazas se derivan de las actividades de riesgo de la sociedad actual. «Así, existe una tensión que llega hasta hoy, entre la necesidad de actuar y la disponibilidad del conocimiento ${ }^{17}$.

Viene la búsqueda del riesgo aceptable a romper este círculo vicioso de la falta de confianza, como queda reflejado en la Figura 2.

\section{FIGURA 2}

La solución del riesgos aceptable al circulo vicioso de la falta de confianza en las politicas públicas sobre riesgos

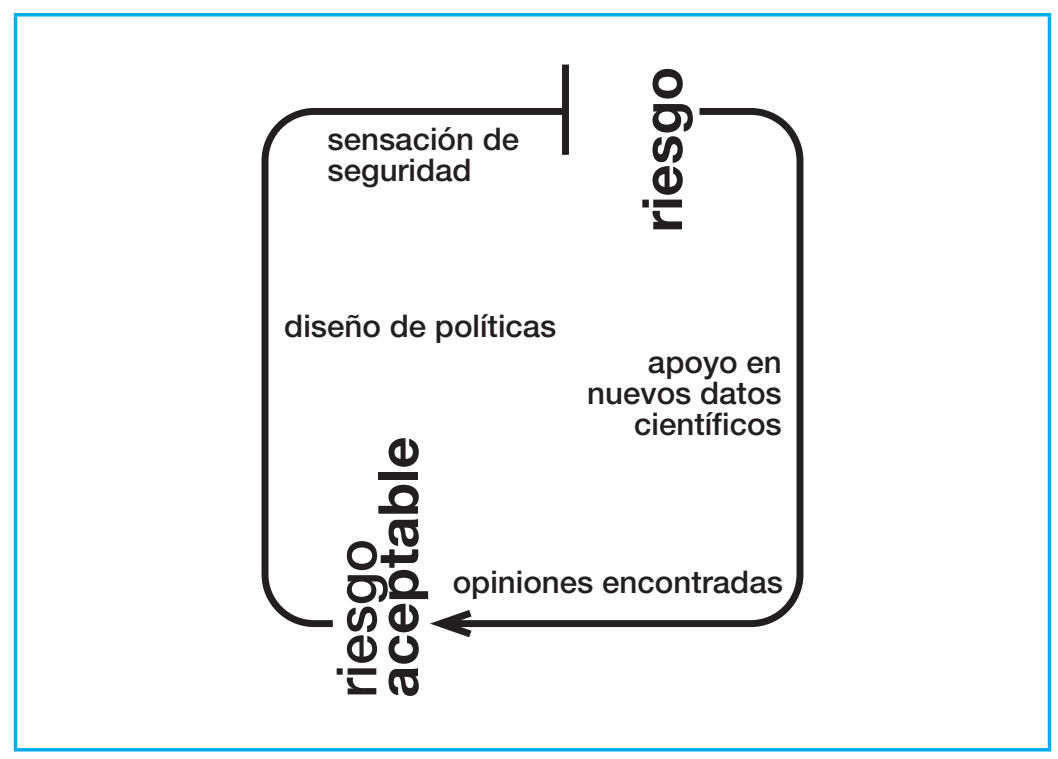

Fuente: Elaboración propia.

La política se transforma en una tarea de predicción que se encarga ahora, no de repartir los beneficios, sino los daños; que ha de satisfacer las demandas de minimización o eliminación del riesgo futuro, o establecer las compensaciones oportunas para reparar los daños.

Pero ya no puede confiar, no puede apoyarse el político para la toma de decisiones, en el criterio de los científicos, y ello por dos razones ya apuntadas: sobre los distintos riesgos, sus orígenes y sus consecuencias, hay

17 Son palabras de William D. Ruckelshaus, antiguo administrador de la EPA estadounidense, que añade: «Para evitar la paralización de la acción protectiva que resultaría de esperar a tener datos 'definitivos', asumimos que tenemos un conocimiento mayor que el que los científicos poseen en realidad y tomamos decisiones basándonos en esa suposición» (Ruckelshaus 1985: 25). 
diferentes puntos de vista enfrentados y los expertos no se ponen de acuerdo. En segundo lugar, la ciencia, los expertos, pueden hacer afirmaciones sobre la probabilidad de que el riesgo se manifieste, sobre las posibles consecuencias para la salud y el medioambiente que el mismo puede tener; pero, ya se apuntó, no es tarea de la ciencia, ni está capacitada para ello, afirmar cuál es el riesgo aceptable y cuál no lo es. Los políticos no pueden, simplemente, adoptar el punto de vista científico, o se verán «atrapados en los errores, modos e incertidumbres del conocimiento científico» (Beck 1998: 10).

Acuden, entonces, a emplear distintos métodos que permitan encontrar ese riesgo aceptable. Los más relevantes se analizan a continuación.

\section{Los métodos para encontrar el riesgo aceptable}

Parafraseando a Lloyd Wright, pudiera decirse que para quien tiene la responsabilidad final de decidir qué riesgo es aceptable, cada método expresa su propio mensaje. Si queremos comprender este mensaje es necesario meditar sobre cómo cada uno de los métodos trabaja con las ecuaciones planteadas, maneja las variables, consume recursos y presenta los resultados. No interesan por tanto, ahora, los detalles técnicos que caracterizan a cada método, pues sobre ellos pueden encontrarse multitud de obras que los tratan con profusión, interesa, sí, penetrar la peculiar racionalidad que los informa y que los dota de una etopeya diferente y específica.

\section{a) Criterio de los profesionales}

Desconocénse los riesgos hasta que no se muestran de una manera conspicua ante la sociedad a la que amenazan, pero ello no quiere decir que no existan y, menos aún, que dejen de ser un problema al que se encargan de dar solución ingenieros, químicos, médicos, etc.

Es a los profesionales a quien se acude cuando se trata de tomar decisiones y diseñar caminos de acción cuando esos mismos riesgos se hacen públicos. La publicidad del riesgo, su constante presencia en los medios de comunicación, su relevancia en las discusiones públicas, no convierten la tarea en sencilla; en nada facilita su comprensión por el que no es profesional. Por el contrario, se ve éste obligado a buscar apoyo en la opinión profesional para defender las decisiones adoptadas o que se pretenden adoptar frente a las opiniones críticas que sin duda alguna aparecerán.

Interesa, pues, saber cómo los profesionales determinan que un riesgo es o no aceptable.

Aunque el proceso de análisis llevado a cabo por el profesional, el analista, sea plenamente científico y, fundamentalmente, el resultado de aplicar los conocimientos inculcados en las etapas de formación -conocimientos testados y contrastados por la experiencia-, no se puede ignorar que el resultado es también fruto de una intuición experimentada y que no se logra únicamente por el mero juego de los elementos inductivos de la ciencia. Es la propia experiencia del profesional, que se guía por estándares implícitos de profesionalismo ${ }^{18}$. El saber que se necesita aquí es el saber preparado, alerta y atento al salto ante las circunstancias más variadas; el saber de aquellas cosas que, por asimiladas, no se recuerdan, pero que actúan como una segunda naturaleza en el profesional.

\footnotetext{
18 «Estos estándares implícitos son lo suficientemente generales como para dar al profesional un sentimiento de cuáles pueden ser acciones aceptables en todos los variados problemas que aparecen.» (Fischhoff et al. 1981: 61).
} 
Se redactan, en ocasiones, estos estándares de comportamiento (Tabla 4), recogiendo las experiencias, los resultados del ensayo y error, del conjunto de profesionales. Algunas de esas compilaciones se convierten en códigos que son establecidos como de obligado cumplimiento por el gobierno y sus agencias.

\section{TABLA 4}

\section{Tipos de estándares empleados por los profesionales para la determinación del riesgo aceptable}

\begin{tabular}{|l|l|}
\hline Tipos de estándares & \\
\hline Éticos & Adoptados por las organizaciones profesionales requiriendo que sus miembros se ajusten en su práctica a determinados principios \\
\hline De calidad & Especifican el tipo e intensidad del esfuerzo que ha de dedicarse a la solución de un problema \\
\hline Técnicos & Especifican los requisitos que ha de tener un sistema \\
\hline De producción & Establecen los límites que han de ser respetados para evitar riesgos \\
\hline
\end{tabular}

Fuente: Fischhoff et al. (1981: 62).

Respecto a las ecuaciones presentadas anteriormente y que han de ser atendidas por el análisis de riesgos, queda claro que aquélla que quedará resuelta a mayor satisfacción por este método, ha de ser la que se refiere a los datos y las técnicas empleadas para la obtención de una respuesta a la pregunta de qué riesgo es aceptable.

Descuídanse, por tanto, las otras ecuaciones que quedan resueltas de manera incompleta y poco satisfactoria.

Los ciudadanos, los afectados, no entienden el lenguaje con que les presentan los resultados de los análisis. Difícilmente asumirán un riesgo como aceptable cuando la misma complejidad de los análisis impide su comprensión y, por el contrario, atemoriza y genera una mayor zozobra e incertidumbre con respecto a los posibles resultados negativos de una nueva tecnología, fuente de energía, procedimiento quirúrgico, etc. «Hay un número determinado de formas en que los expertos fallan, deliberada o inadvertidamente, a la hora de informar al público. Una es no contando la historia completa sobre los riesgos que ellos conocen mejor, porque temen que la información genere ansiedad en el público, porque su trabajo no consiste en la diseminación de la información o porque tienen interés en dejar que las cosas sigan como están» (Fischhoff, Slovic y Lichtenstein 1982: 247) ${ }^{19}$.

La existencia de estándares determinados para los distintos profesionales analistas del riesgo no garantiza, empero, la existencia de acuerdo entre ellos ${ }^{20}$. Dilúyese la distinción entre científicos y público en general porque aquéllos, igual que éstos, desconocen cuál será el resultado de su investigación, a pesar de que en la búsqueda por el apoyo político para su desarrollo afirmen lo contrario. Así las cosas, la política, que ha de satisfacer las demandas de minimización o eliminación del riesgo futuro, o establecer las compensaciones oportunas para reparar los daños, ya no puede confiar, no puede apoyarse para la toma de decisiones, exclusivamente en el criterio de los científicos ${ }^{21}$.

${ }^{19}$ Además, el peligro de dar información incompleta es que ocasiona uno de los dos resultados siguientes: o bien cuando son descubiertas las omisiones dan lugar a un importante descrédito de los expertos; o bien las omisiones por no aparecer no son tenidas en cuenta nunca.

${ }^{20}$ Es cierto que los expertos están acostumbrados a los desacuerdos, pero lo que es nuevo en la ciencia es que no se acaba de comprender muy bien en torno a qué existe el desacuerdo. Cuando las cosas están así, la reacción es profundizar aún más en los análisis para buscar mayores evidencias.

${ }^{21}$ Más aún, «la demanda de una 'ciencia sólida’ se convierte en una excusa para diferir la decisión (...) De hecho, lo que los encargados de tomar las decisiones están haciendo es agarrarse a los pelos de la incertidumbre porque les permite no hacer nada y esperar que las cosas salgan bien después de todo» (Tindale 1998: 64-67). 
Respecto a la última ecuación, al no estar la certidumbre científica garantizada, los fundamentos científicos de las decisiones adoptadas son puestos en duda a partir de posturas igualmente científicas pero divergentes, y cada uno de los grupos de interés implicados hace uso de distintos expertos. Se origina una advocay science (HorlickJones y De Marchi 1995) en la que se emplean expertos contratados por los distintos grupos competidores para destruir la postura de sus contrarios ${ }^{22}$.

A la falta de resolución de estas ecuaciones, añádese, además, un fenómeno característico de la relación que la sociedad actual mantiene con el riesgo: la aparición de nuevos expertos: "Coexisten nuevas formas de pericia profesional con la tradicional, a veces de modo complicado. Están emergiendo nuevas formas de pericia 'alternativà que están más firmemente fundamentadas en la experiencia de cada día y en los intereses de los pacientes, activistas y negocios, más que surgiendo de los frutos de una investigación académica 'imparcial' (...) Muchas de estas fuentes de pericia alternativa no están constreñidas por los estándares de control de calidad (no importa cuán imperfectos) que son típicos de la pericia ortodoxa profesional» (Horlick-Jones, 2004: 110).

En resolución, tras este método, -el juicio de los profesionales-, se esconde una fe casi ciega en el conocimiento de los hechos, la fiabilidad de los datos, el rigor de la experimentación, la posibilidad de extrapolación de los resultados, la toma en consideración de la incertidumbre y su manejo a través de modernas técnicas matemáticas. Se considera, por tanto, el riesgo como algo objetivo, capaz de ser sometido al método científico: el riesgo es real y la investigación científica proporciona una mayor fiabilidad en la predicción que los juicios del hombre de la calle (entendiendo por éste a un hombre razonable). El problema es que esa afirmación lleva implícita otra que no es cierta; el asumir que la interpretación rigurosa de la teoría de la probabilidad es un marco conceptual superior para la comprensión del riesgo.

\section{b) Preferencias reveladas e implicitas}

No puede ningún método computacional ni ningún juicio profesional llegar a establecer que vivir dos meses en Denver es tan arriesgado como beber medio litro de vino, tomar 40 cucharadas de mantequilla o estar una hora en una mina de carbón. Sin embargo, estos compendios de riesgos existen y con ellos se pretende ayudar a tomar decisiones a los políticos encargados de elaborar las políticas públicas encaminadas a hacer frente a los riesgos de la sociedad moderna. Fundaméntase esta pretensión en la creencia de que no es posible analizar ningún riesgo de manera adecuada en un corto período de tiempo, sin haber experimentado un proceso de obtención de beneficios/padecimiento de fatales consecuencias por parte de la sociedad, es decir, sin un conveniente período de ensayo y error.

Sólo tras el período de experimentación puede establecerse con visos de certidumbre que un riesgo es aceptable, que otro no lo es, que las consecuencias de aquél pueden asumirse, que las de éste no.

Es la sociedad en su conjunto la que, por tanto, toma la decisión final, responde a la pregunta de cuál es el riesgo aceptable. No se trata de un grupo de personas, profesionales experimentados, científicos, los que señalan qué riesgos es posible correr, cómo evitar unos, cómo reducir otros, etc. La recomendación con respecto a los nuevos riesgos está clara: «extrapólese el nivel de riesgo que se aceptó en el pasado.»

22 Es en los tribunales de justicia donde puede apreciarse este fenómeno en su mayor intensidad. Para Peter Huber 1991: 13), esta tendencia comenzó con las ideas de Guido Calabresi, en los años 60, quien pretendía racionalizar todo el proceso judicial. El resultado es, según este autor, que «muchas defensas venerables basadas en el contrato, el consentimiento, la asunción del riesgo, la elección informada, la costumbre social, y el cuidado razonable habían limitado la responsabilidad mucho antes de que herreros, técnicos de laboratorio o físicos nucleares fueran llamados al estrado de los testigos (...) Conforme los tribunales se deslizaban hacia la responsabilidad absoluta por los daños causados, cada vez más casos comenzaban a girar por completo sobre la ciencia de la causa y el efecto.» 
Esta racionalidad basada en la experiencia es la que sustenta los métodos de análisis de riesgos de las preferencias reveladas y de las preferencias implícitas. Se considera, en el primero de los casos, que la sociedad ha alcanzado un óptimo en la gestión del riesgo, logrando el equilibrio entre beneficios y riesgos que permite la actual tecnología. A partir de aquí, cualquier nuevo riesgo que aparezca habrá de ser aceptado si no supera los límites existentes para riesgos similares del pasado, ofreciendo beneficios parecidos. De manera muy similar, las preferencias implícitas se revelan en la historiografía de leyes, regulaciones, indemnizaciones, etc., que reflejan los distintos compromisos que ha alcanzado la sociedad en torno al riesgo que se acepta a cambio de un determinado beneficio ${ }^{23}$. Quienes defienden este método no están afirmando, sin embargo, que las reglas existentes, que los acuerdos alcanzados, sean perfectos $^{24}$ pero sí que son la mejor tentativa que existe para alcanzar la satisfacción del deseo de seguridad de la gente en un mundo de riesgos.

Su debilidad, es la debilidad de la democracia misma: concíbense las leyes con urgencia y están pobremente escritas, en ocasiones; se extiende su aplicación a situaciones no imaginadas cuando fueron redactadas; su formulación precisa puede reflejar efímeras coaliciones políticas o preocupaciones públicas (Fischhoff et al. 1981: 85).

No resuelven estos métodos la ecuación referida a la representación del riesgo, a la percepción que del riesgo tienen los ciudadanos. Congelan y pretenden prolongar en el futuro el resultado particular de un determinado momento. Se considera a los ciudadanos capaces, por medio de los espontáneos arreglos que entre ellos se producen, de equilibrar las realidades tecnológicas y políticas, pero una vez que se ha alcanzado ese equilibrio, se pretende que sea imperecedero y válido para un futuro que puede no parecerse en nada al momento actual. La presentación del riesgo es la presentación de un riesgo del pasado.

Se descuidan, también, las restantes ecuaciones. No coincide el juicio de los ciudadanos con respecto a qué riesgos son aceptables, con aquéllos que emiten los profesionales, los expertos, que en estos métodos no poseen la última palabra. Las distintas heurísticas, atajos para la reflexión, provocan que haya un importante distanciamiento entre el juicio del experto y el del ciudadano. «Aunque las personas puedan conocer las estadísticas, el riesgo significa algo más que mortalidad, y el contenido concreto de ese significado puede cambiar de una fuente de peligro o tecnología a otra, y de una persona o grupo de personas respecto a otras con diferentes creencias y sistemas de valores, y también según los diferentes contextos» (Puy 1995: 98).

En la aceptabilidad del riesgo influyen, además, otra serie de características que pueden definirlo: que sea voluntario o involuntario, crónico o catastrófico, común o terrorífico, cierto pero no fatal o cierto y fatal, conocido o desconocido, inmediato o pospuesto, controlable o no controlable, nuevo o antiguo (Slovic, Fischhoff y Lichtenstein 1979).

Los expertos miran con desdén y desconfianza los juicios de los ciudadanos que no suelen coincidir con sus apreciaciones. Se refleja en ello la dicotomía entre el riesgo objetivo y el percibido, que no será tratado aquí sino para señalar que, en relación con la segunda ecuación, la relativa a al finalidad política, resulta obvio que reconocer que el riesgo es una construcción social, una apreciación subjetiva, implica reconocerlo al tiempo como asunto político (lo que no ocurría en el método previo, donde los profesionales acaparan la discusión y la tarea del político

${ }^{23}$ Uno de los ejemplos de la aplicación de estos métodos de análisis es el establecimiento del valor estadístico de una vida. A través de encuestas realizadas a trabajadores sobre cuánto estarían dispuestos a pagar por reducir el riesgo (Willingness To Pay, WTP), se obtiene el valor monetario de una vida. Krupnik et al. (2002) establecieron, para Canadá, el valor de una vida entre 506.000 y 933.000 dólares; para Alberini et al. (2002), el resultado fue de 700.000 a más de millón y medio de dólares, en los Estados Unidos. Sobre este asunto pueden verse Tsuge (en prensa), Hammitt y Liu (2004), Viscusi (2004) y Thaler y Rosen (1976).

${ }^{24}$ Lo mismo afirma Lindblom (1965) respecto a la democracia. 
es simplemente adoptar una de las opciones científicas presentadas), y ver el análisis del riesgo como un instrumento político (Otway y Thomas 1982).

Por último, los recursos destinados a este tipo de análisis se diluyen en el proceso histórico de convivencia de la sociedad con el riesgo. Grupos de intereses defenderán posturas concretas aquí y allá, donde surjan los problemas. Los riesgos no son vistos como formando parte de un todo complejo y global que requiere soluciones relacionadas y la dedicación de esfuerzos específicos.

\section{c) Análisis coste-beneficio}

Es éste el método de análisis de riesgo más empleado, al que se le concede un mayor crédito y que disfruta de una más extendida fama. Sea por el atractivo que supone su argumentación, sea porque no es, en definitiva, sino la aplicación a un caso especial del normal razonar humano, desde que en los años 30 comenzara a llamar la atención del Cuerpo de Ingenieros del ejército norteamericano, no ha dejado de ser empleado y defendido con profusión.

Injertado en el análisis de riesgos desde la floreciente teoría económica, consiste en aplicar los mismos principios que rigen la toma de decisiones en el mercado: se trata de maximizar los beneficios minimizando los costes. De todos los proyectos que se abren como posibilidades ante el individuo actuante, nos dice, se escogerá -al menos, si el individuo actúa racionalmente- aquél que suponga una mayor recompensa. En el terreno del riesgo y siendo la sociedad protagonista, se optará por aquella alternativa que acabe por suponer un mayor beneficio para el mayor número.

Se encuentra tras todo ello una justificación que descansa en el concepto del «óptimo de Pareto» ${ }^{25}$ ligeramente modificado para adaptarlo al mundo del riesgo. No se trata ahora de lograr el equilibrio de mercado: la tarea es decidir quién va a padecer los adversos e indeseables efectos del desarrollo de una determinada actividad arriesgada. No siendo posible alcanzar el riesgo cero, no es posible atinar a conseguir un óptimo de Pareto puro. Menos riesgo para mí implica más riesgo para los demás. «El problema general es que los esfuerzos para combatir un determinado riesgo pueden, de manera no intencionada, incrementar «riesgos secundarios» (...) La transferencia del riesgo es un fenómeno extendido en las decisiones que toma la gente para proteger la salud y el medioambiente» (Graham y Baert Wiener 1997: 2).

Modificada pues la idea paretiana, el objetivo del método de análisis de coste beneficio puede enunciarse así: «Adóptese como riesgo aceptable aquél que ofrezca a quienes obtendrán ganancias de la práctica arriesgada, unos beneficios que compensen las pérdidas de aquéllos sobre quienes recaerán los efectos negativos no deseados». Se sigue, por tanto, que es ineluctable establecer un proceso de compensación que permita que fluya parte de los beneficios hacia quienes sufren las pérdidas, bien de manera directa a través de indemnizaciones, bien de manera indirecta a través de los impuestos. Aquí, sin embargo, no interesa este corolario, sino repasar nuestras ecuaciones para ver en qué medida quedan satisfechas con este método de análisis.

El análisis coste beneficio es un procedimiento formal de análisis ${ }^{26}$ tremendamente exigente en cuanto a la información de que hay que disponer para llevarlo a término. Así, es preciso conocer todas las posibles vías de ac-

${ }^{25}$ Una definición típica del principio de eficiencia de Pareto puede ser la siguiente: es aceptable aquella solución económica que beneficia al menos a un miembro de la sociedad sin causar perjuicio o daño a ningún otro.

${ }^{26}$ Otro procedimiento formal de análisis es el que aplica la teoría de la decisión, o el análisis de decisiones. Este procedimiento se fundamenta en las obras de los iniciadores de la teoría de juegos Neumann y Morgensten. No se tratará en estas páginas esta teoría por ser eminentemente prescriptiva: exige, para que se cumplan sus axiomas, aceptar un determinado modelo de individuo y de racionalidad, caracterizada fundamentalmente por el axioma de la transitividad en la elección, que, sin embargo, se parece poco a los hombres reales. 
ción entre las que resulte factible optar ${ }^{27}$ y deben tenerse presentes las relaciones que entre todas ellas existen. Pero la piedra angular sobre la que descansa el método, es la posibilidad de traducir las consecuencias, todas, de esas alternativas a una unidad de cálculo común que permita medir el valor que se les otorga: dinero.

Sencilla resulta, pues, la aritmética a realizar: una simple resta -siendo el minuendo el beneficio y el sustraendo el coste- determina la aceptabilidad o no de un riesgo dado.

La formalidad aparente y el rigor matemático de este método no pueden ocultar, sin embargo, que no soluciona de manera totalmente satisfactoria las distintas ecuaciones que hemos presentado. En la primera de ellas se encuentra ya la más grave e insuperable dificultad, que pone en cuestión la validez completa del procedimiento. Los datos necesarios para estimar los beneficios y las pérdidas no son sencillos de obtener, planteándose de nuevo la cuestión de si resulta oportuno proceder a mayores inversiones de recursos con la finalidad de disponer de datos más refinados y ajustados a la realidad que se analiza, lo que, indudablemente supone un coste que, curiosamente, no es tenido en cuenta por el propio método. Sin embargo, el análisis coste beneficio exige que toda la información necesaria para desarrollarlo se encuentre ya disponible. Pero, cuando se trata de riesgos, los datos suelen caer dentro de una de las siguientes tres categorías: o bien no existe ninguna fuente de información directa respecto al riesgo que se está considerando -aunque, no obstante, pudiera existir esa información con respecto a riesgos similares -; o bien tanto la evidencia directa como la indirecta de la que se dispone es pobre o incompleta y hay que acudir al juicio subjetivo o intuición de los expertos; o bien no existe ningún tipo de evidencia, y los expertos no tienen fundamentos sobre los que apoyar sus juicios subjetivos ${ }^{28}$.

Tampoco se satisface la ecuación de los ciudadanos. Estriba el principal de los problemas en que la evaluación de las consecuencias depende de la estructura de valores y preferencias de cada individuo o sociedad. Steven Kelman $(1981)^{29}$ señala que reducir todas las consideraciones a un análisis de ese tipo contradice nuestros valores sociales. El bienestar personal, la protección del medioambiente y otros valores especiales como la libertad de expresión o el derecho al voto no tienen precio; ciertas regulaciones que no pueden justificarse a través del análisis coste-beneficio siguen siendo correctas si reflejan los valores de los ciudadanos. A ello hay que añadir que en una sociedad, no todos los individuos coinciden en los beneficios que esperan. Algunas actitudes podrían calificarse como poco juiciosas por lo que al riesgo se refiere, pero tal juicio corresponde a doctrinas éticas que determinan la normalidad o la perversidad de las acciones, según su adecuación a preestablecidas escalas valorativas que aspiran a fijar lo que es el bien o el mal. Semejante postura es ajena al análisis de riesgos; los conceptos morales carecen de vigencia cuando se trata de establecer el riesgo aceptable ${ }^{30}$. Habrá quienes gocen corriendo riesgos que otros prefieren evitar, pero sería imposible introducir en el cálculo del coste beneficio todas y cada una de las preferencias individuales: tal cosa está más allá de la capacidad del análisis algebraico que propone el modelo.

\footnotetext{
${ }^{27}$ Cuando sólo una sea la vía de acción, el análisis no aportará soluciones alternativas; se limitará a determinar que es inadecuada por demasiado costosa.

${ }^{28}$ El mismo Pareto llega a una conclusión similar cuando habla del modo de conocer el equilibrio económico, al afirmar que la hipótesis más favorable, -»supongamos que hemos triunfado sobre todas las dificultades para llegar a conocer los datos del problema»-, es una hipótesis «absurda» (Pareto, 1966: 233).

29 Para este autor, «presumiblemente, por tanto, aquellos que instan a los reguladores a hacer un mayor uso de la técnica (el análisis costebeneficio) tienen una receta mayor en mente». Y llega a las siguientes conclusiones: «(1) En las áreas de regulación del medioambiente, la seguridad y la salud, puede haber muchos casos en los que una decisión particular puede ser correcta incluso aunque sus beneficios no superen los costes. (2) Hay buenas razones para oponerse a los esfuerzos de pasar a un valor en dólares beneficios y costes que están fuera del mercado. (3) Dada la relativa frecuencia con que ocurre que uno no desearía usar el test beneficio-que-supera-el-coste como regla de decisión en áreas de regulación medioambiental, de seguridad y de salud (...) no se justifica dedicar mayores recursos a la producción de datos para los cálculos coste-beneficio o a emprender esfuerzos para 'difundir el evangelio' del análisis coste-beneficio más lejos» (Kelman 1981: 33).

${ }^{30}$ Fischhoff (1994) cae sin embargo en este error, puesto que aunque reconoce el problema de que respecto al riesgo existen diferencias individuales, no da una respuesta adecuada; argumenta que más que tener que satisfacer todo posible conjunto de valores, la tecnología debería producir conjuntos de consecuencias aceptables para individuos que tienen valores «razonables».
} 
Por lo que se refiere a la ecuación política, en poco ayuda este análisis formal del riesgo a determinar con acierto una u otra política. Es innegable que la argumentación que ofrece es un arma poderosa a la hora de justificar una decisión, pero nada puede decir sobre lo acertado de la misma. Es necesario insistir, para que esto se entienda, en que el problema no es que la cantidad de datos que sería necesario analizar resulte imposible de manejar; puede imaginarse un futuro en que las máquinas ayuden a manipular cantidades de datos muy superiores. Tampoco es que el político, disponiendo de esa información, no pueda utilizarla con más o menos acierto ${ }^{31}$. Lo que interesa destacar es que, la información necesaria para la realización de un análisis coste beneficio nunca estará disponible en su totalidad. Nunca se tendrá la información necesaria para enunciar siquiera el cálculo que permitiría describir una situación de beneficio neto, porque esa información está dispersa en todos y cada uno de los ciudadanos. No hay encuesta de opinión pública, ni referéndum que coloque al político en una situación tal que le permita tomar una decisión con la certeza absoluta de que será correcta ${ }^{32}$.

Por último, son los distintos grupos de interés, enfrentados en la arena del riesgo aceptable, quienes encuentran en este método una provisión de argumentos para la defensa de sus posturas. La situación es similar a la que provocaba la «advocay science» de que se habló más arriba, por lo que no será necesario insistir más en ello. Pero sí es oportuno señalar, de nuevo, que al no reseñarse en el epígrafe costes del análisis aquéllos que necesariamente se producen al llevar a cabo el mismo, la decisión de profundizar más en él, refinar más la obtención de datos, su procesamiento, etc., dependerá del esfuerzo que cada parte interesada decida invertir según el beneficio que espera, no ya de la evitación o asunción del riesgo, sino del hecho de que la políica pública desarrollada sea afín a su postura.

\section{Conclusiones: del riesgo aceptable al «marketing» de confianza}

Afirmar que determinado riesgo es aceptable, ¿quiere decir que es tolerable ${ }^{233}$ Probablemente haya que responder no a esta pregunta. Si se analiza con un poco de detenimiento lo que con ella se quiere decir se descubrirá que supone poner en cuestión el mismo concepto de riesgo aceptable. El término aceptable parece implicar una voluntariedad a la hora de asumir un riesgo; resulta evidente, no obstante, que tal cosa no es exacta. Los riesgos, en realidad, se imponen y sólo queda aceptarlos como consecuencia inevitable de la modernidad ${ }^{34}$.

Por otro lado, las personas no eligen de entre los distintos riesgos aquéllos que son aceptables. No escogen, de hecho, entre riesgos en absoluto; eligen entre opciones distintas que tienen al riesgo como una de las dimensiones que serán estimadas a la hora de optar por una u otra. Una dimensión entre otras más y, a veces, no la más importante $e^{35}$.

${ }^{31}$ Aunque no está de más citar a Cicerón (De Re Publica): «Nunca ha existido un genio tan vasto que lograra que nada se escapase a su atención, ni todos los genios del mundo unidos en una única mente, podrían, en los límites de una sola vida, ser tan preclaros como para abarcar y armonizar todo, sin la ayuda de la experiencia y la práctica.»

32 Aunque sólo sea porque hay una diferencia entre las opiniones expresadas y las conductas reales frente al riesgo.

33 Son numerosos los autores que han apostado por este término frente al de riesgo aceptable, por ejemplo Pidgeon et al. (1992) o Kates y Kasperson (1983).

34 «Aceptable es lo que la gente acepta, tanto si lo hace de forma voluntaria, sin saberlo, o porque no tiene más remedio. Nadie tiene la garantía absoluta de la seguridad. Sólo podemos escoger entre opciones, las cuales, si los analistas no se equivocan, podrían tener diferentes probabilidades» (Cumming 1982: 42. Citado en Puy 1995: 103).

35 Muchas otras críticas podrían hacerse al término de riesgo aceptable, al concepto mismo. Por ejemplo, que lo que es aceptable muda con las circunstancias sociales, políticas o económicas y lo que era aceptado en un momento puede no serlo más tarde. O que sea un término demasiado estrecho como para que pueda con él decidirse sobre la aceptación de las nuevas tecnologías. Aún estando de acuerdo con esas críticas, no puede ignorarse que tales posturas poco ayudan a quien tiene que tomar una decisión. 
Vivir en una sociedad que puede ser caracterizada por el riesgo genera, necesariamente, ansiedad. El ser humano, siempre que le resulta posible, trata de reducir la ansiedad que la incertidumbre con respecto al futuro provoca, de modo que si le dan la posibilidad prefiere evitar las situaciones de riesgo. Es más, «prefiere que se le diga que los riesgos han sido gestionados por profesionales competentes y son, por lo mismo, tan pequeños que no necesita preocuparse por ellos» (Slovic 2006: 185).

Se espera que el gobierno los regule en beneficio de la sociedad. Se enfrenta el decisor público a la ineludible tarea de tomar una resolución ${ }^{36}$. Es cierto que el margen de poder concedido es amplio: quien controla la definición del riesgo, controla la solución racional del problema. Pero, igualmente y como se ha visto, los distintos métodos analizados ${ }^{37}$ no resuelven satisfactoriamente el problema. Los tres comparten una racionalidad que olvida que no hay un riesgo objetivo absoluto, que el riesgo es sintético, por decirlo de una manera breve, es decir, se construye, se elabora, se sintetiza a partir de las recompensas esperadas, el peligro percibido y las experiencias pasadas (véase Figura 3) 38 .

\section{FIGURA 3}

Influencias determinantes de la actitud ante el riesgo

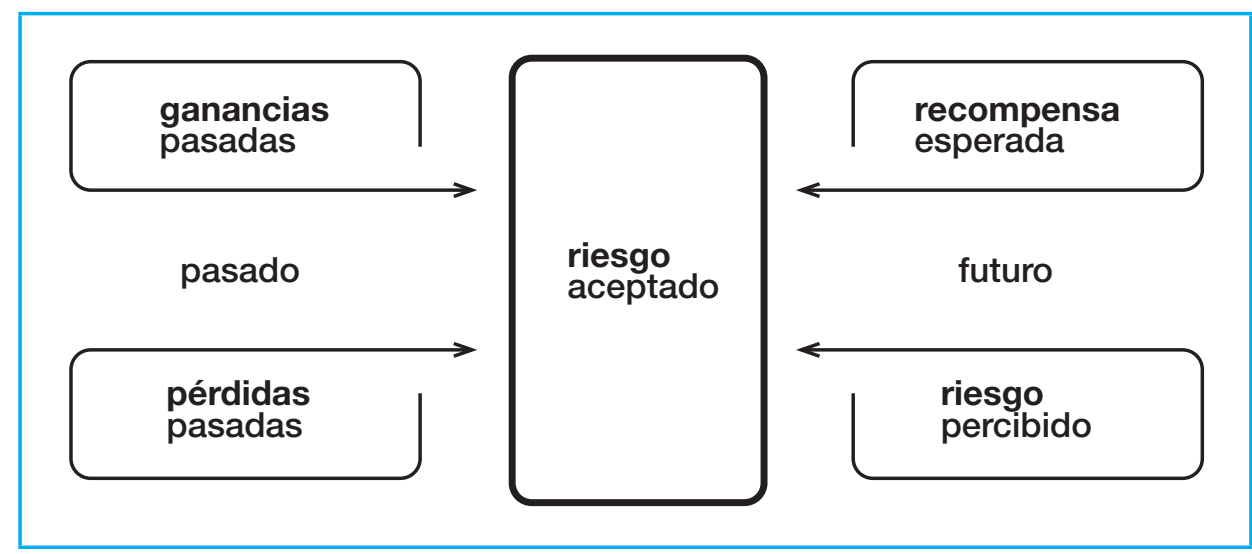

Fuente: Elaboración propia.

Los métodos empleados en la búsqueda del riesgo aceptable exigen poner en práctica lo que acertadamente Oakeshott (1991) caracterizó como racionalismo moderno, que reduce la razón a un conocimiento técnico explícito, claramente articulado y centralizado en los científicos que lo generan y monopolizan, excluyendo todo tipo de conocimiento práctico o tradicional, disperso y tácito. Hemos visto que esta racionalidad moderna no es capaz de aportar soluciones que satisfagan todas las ecuaciones del análisis de riesgos. Ciertamente, el político no puede dejar de emplear este tipo de conocimiento y aplicarlo, si se quiere, al segundo, pero no puede, tampoco, fundamentarse en él exclusivamente para dar soluciones satisfactorias a todas las ecuaciones: ofrecer seguridad al ciudadano, aceptar los criterios científicos no discutidos, no desatender ningún interés legítimo.

36 Sobre este tema puede verse el estudio realizado por Vanaclocha, Martinón y Losada (2005).

37 Fischhoff et al. (1981) llegan a una conclusión similar respecto a los métodos que estudian: ninguno de ellos responde de manera satisfactoria a la complejidad del problema que plantea el riesgo aceptable y, además, ninguno de ellos está libre de valores, libre de apreciaciones y valoraciones subjetivas que permitan calificar el resultado de objetivo.

38 Adams (1985 y 1988), postula lo siguiente: (1) todo el mundo tiene propensión a correr riesgos, (2) esta propensión varia de individuo a individuo; (3) esta propensión se ve influenciada por las recompensas que puede reportar la acción arriesgada; (4) cada individuo tiene una percepción del riesgo determinada por su experiencia o su forma de ver el mundo; (5) las decisiones individuales de asumir un riesgo no son sino el balance realizado entre la percepción del riesgo y la propensión a correr riesgos; (6) las pérdidas son, por definición, la consecuencia de asumir riesgos: a mayor cantidad de riesgos, mayores serán, en término medio, las pérdidas o las ganancias. 
Se acepta comúnmente, que si no puede darse una garantía de seguridad se demandará una mayor información respecto a los riesgos, con la finalidad de adoptar decisiones con el menor margen de error posible ${ }^{39}$.

Se descubre así otra variable que interviene en el juego decisorio: la comunicación. El riesgo se percibe y comunica. Así, no ha faltado quien considere a la comunicación de masas como responsable principal de la especial situación de ansiedad, de preocupación extrema ${ }^{40}$, ante el riesgo que caracteriza a la sociedad en que vivi$\operatorname{mos}^{41}$. «La fuerte mediatización de un riesgo aumenta considerablemente la sensación de peligro. Inversamente, cuando son poco mediatizados, los riesgos son a menudo subestimados por la población» (Denise-Lempereur, 2000: 110).

Es precisamente el aspecto de la comunicación el principal ausente en los métodos analizados para la búsqueda del riesgo aceptable. Rara vez la presentación de los resultados dejará de estar influenciada por las formas y peculiaridades del método empleado, pero ello no quiere decir que los resultados sean comprendidos por aquellos que, en definitiva, han de aceptar el riesgo. Estaríamos ante una situación ideal si se lograra una correlación perfecta entre el fondo y la forma, pero hoy se considera, sin embargo, que no es necesario -y no sería muy exagerado decir que casi se considera proscribible- el que la presentación de los resultados induzca a pensar en los medios por los que han sido alcanzados, como si aquél a quien va destinada la información fuera incapaz de comprender los mecanismos internos que lo convierten en posible afectado por las adversas consecuencias de una actividad arriesgada pero calificada, por otros que no son él mismo, como aceptable. En pocas ocasiones puede verse con tanta claridad, como ocurre cuando se trata de riesgos, una tan neta separación entre la técnica y el resultado. Y si bien es cierto que es pecaminoso mentir y no siempre lo es ocultar la verdad, esta última postura dificulta alcanzar el objetivo que persigue el político: transmitir sensación de seguridad. No otra cosa es lo que, en la sociedad del riesgo, demandan los ciudadanos: seguridad, confianza.

Tal vez aquí, como en muchos otros casos, más que molestar la ocultación, lo que más desasosiegue al ciudadano, al afectado por el riesgo, sea la sensación de que se ha pretendido que ingiera una píldora que no desea tragar, que se haya cometido un abuso de confianza a cuenta de su pretendido desconocimiento; de ahí que la reacción más común cuando se presenta una crisis ${ }^{42}$ sea la de la indignación. Y si bien es verdad que, al contrario que en la Grecia clásica, de la que se dice que cualquier ciudadano podía corregir el verso del mejor poeta, hoy el conocimiento no es patrimonio general y, menos aún, en lo tocante a los riesgos modernos, ha de comprenderse que esos riesgos afectan a todos, a la vida de cada ciudadano y que, por lo mismo, es imposible dejarlos a un lado.

Se necesita, por tanto, una comunicación de los riesgos capaz de generar confianza. La situación puede presentarse igualmente aplicando nuestro modelo de ecuaciones, variables y actores. Así, una nueva y trascendente ecuación ha de ser resuelta (Tabla 5).

${ }^{39}$ Hay quien, incluso, yendo un paso más allá de la información, ve la solución en la participación. En este sentido puede citarse la propuesta de una democracia deliberativa que hace Arias Maldonado (2003: 238), quien citando a Eckersley, dice que stodos aquéllos potencialmente afectados por los riesgos deberían tener una oportunidad significativa de participar, o de ser representados en la adopción de las decisiones o la definición de las políticas que generan tales riesgos». del miedo».

${ }^{40}$ Incluso miedo, como dice Aguilar (2003: 63): «El tipo de riesgo que impera en nuestros días es el que explica que vivamos bajo el signo

${ }^{41}$ Por ejemplo, el informe del Health and Safety Executive del Reino Unido, titulado Use of Risks Assessment Within Governmental Departments, señala: «La conciencia del riesgo de viajar en avión tras un accidente de aviación puede ser amplificada a través de un importante volumen de información, con expertos científicos desafiándose los unos a los otros, la dramatización del asunto y el uso de terminología e imágenes cargadas de emotividad por los medios de comunicación. Esta percepción puede ser incluso más amplificada o atenuada dependiendo de sus efectos en la comunidad o la sociedad entendida como un todo» (HSE, 1996: 9).

${ }^{42}$ Una definición sencilla y escueta de crisis es la que afirma que una crisis es un análisis de riesgos mal hecho. 


\section{TABLA 5}

La comunicación del riesgo

\begin{tabular}{|l|l|l|}
\hline Ecuación & Variable & Actores \\
\hline comunicación & confianza & político/ciudadano \\
\hline
\end{tabular}

No se trata ya, pues, de afirmar que determinado riesgo es aceptable, que aquéllos otros no lo son y que en función de ello se adoptan determinadas políticas. Se trata de crear, de generar, nuevas formas para comunicar el riesgo, la información referente a los diferentes riesgos a los que se enfrenta la sociedad. Nuevos índices, renovadas analogías, impactantes formas de presentación, innovadoras técnicas que reflejen de manera comprensible las estadísticas, vías creativas por las que hacer llegar al público a una comprensión casi intuitiva del riesgo, etc., son los retos que se tienen por delante. En definitiva, podríamos decir que se trata de elaborar, de practicar un «marketing» de confianza, entendiendo este término no en el rígido y estrecho sentido de una técnica de publicidad; no se trata de eso, sino en el sentido de un marketing con mayúsculas, que busca, que "moviliza» generando mutua confianza. Se rompería, por este medio y de una manera más decisiva, el círculo vicioso de la desconfianza que se presentó más arriba. No se trata ahora de calificar un determinado riesgo como aceptable y comunicar esta decisión a los afectados, que se limitarían a asumirla como propia. El círculo desparece dejando en su lugar un proceso que genera confianza.

\section{FIGURA 4}

\section{La comunicación del riesgo}

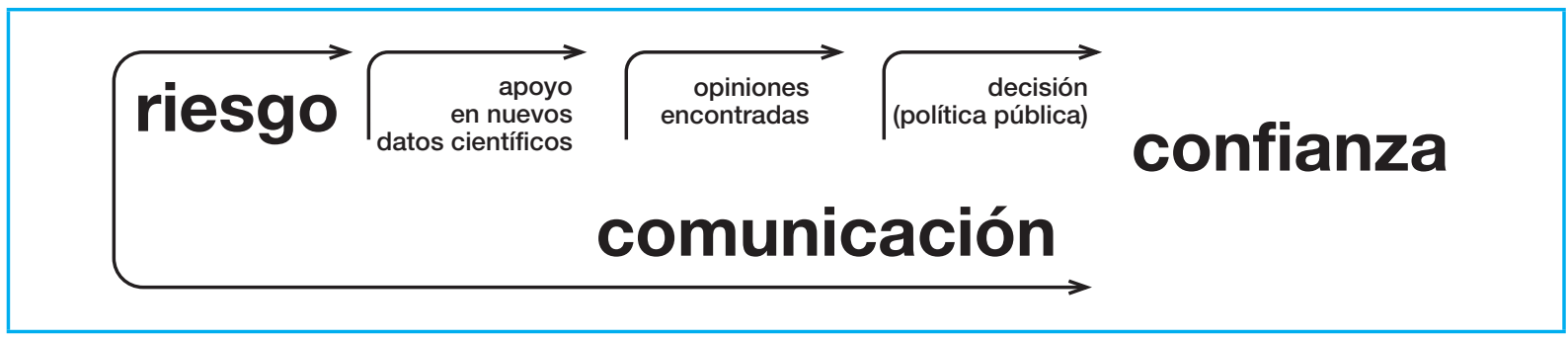

Fuente: Elaboración propia.

Esto implica, desde luego, tener en cuenta las distintas percepciones del riesgo que existen en la sociedad. Porque no existe una única actitud ante el riesgo. Se exige, por tanto, en primer lugar, una escucha atenta, de todos los segmentos de ciudadanos que puedan distinguirse con respecto a los riesgos, desde aquéllos que están directamente involucrados en la realización de la actividad arriesgada, pasando por aquéllos que se verán directamente afectados por la misma y llegando a los más lejanos, aquéllos que sólo de manera esporádica se verán perjudicados por ella. Escuchar con atención sus necesidades, distinguiendo las que son imprescindibles, de las que son básicas o importantes o incluso estratégicas. Sólo a partir de aquí podrá comunicarse el riesgo. Se trata de no quedarse en una comunicación que facilita información al ciudadano, conocimiento, sino de avanzar dos pasos más: superar la comunicación que logra la comprensión del fenómeno para llegar a la comunicación que implica, que genera confianza, que mitiga la ansiedad social.

No se trata, pues, de comunicar como de costumbre, sino de comunicar de una determinada manera, con unas formas concretas o, por decirlo con otras palabras, la comunicación de la que se habla debe interrumpir el discurso habitual sobre los riesgos. No se trata de las noticias que aparecen en la prensa y que reflejan por lo común 
desgraciados accidentes o temibles estadísticas. No debe ser una comunicación que se busca, sino que se encuentra, que sale al camino del ciudadano, que le aparece a cada paso, porque a cada paso se encuentra con nuevos riesgos. Además, debe ser repetitiva: sólo se generará confianza si se está comunicando de manera continua, si se está garantizando, de este modo, los riesgos son preocupación ineludible del político, que está atento a ellos, que forman parte de sus ocupaciones cotidianas, que se trabaja en ellos sin descanso y no de manera esporádica, casual y sin criterio, o sólo cuando las crisis aparecen, cuando ya es demasiado tarde. Por último, la comunicación debe poseer automatismo. Como si de un acto reflejo se tratara, todo riesgo debe ir acompañado de una comunicación que refleje que se tiene en cuenta, que se analiza, que se reflexiona sobre él, que se lo estudia, aunque sea para concluir que nada puede decirse, que nada se sabe sobre su probabilidad y sus consecuencias.

Se pretende con ello generar en el ciudadano, primero, el convencimiento de que los problemas que generan las actividades de riesgo son tenidos en cuenta, que se analizan, que se estudian, pero, además, lo que es más importante, se generará una sensación de confianza, basada también en la difusión del conocimiento, capaz de dar lugar a la adhesión con respecto a las políticas adoptadas. Si el problema está en generar confianza, en transmitir la sensación de que las decisiones tomadas responden, de verdad, a una idea fiel de lo que se entiende por riesgo aceptable, es fundamental comunicar sobre el riesgo y es ésta la tarea que de manera ineludible ha de emprenderse.

\section{REFERENCIAS BIBLIOGRÁFICAS}

Adams, J. (1985), Risk and freedom: the record of road safety regulation. Londres: Transport Publishing Projects.

- (1988), «Evaluating the effectiveness of road safety measures», Traffic Engineering and Control.

- (1995), Risk. Oxon: Routledge.

Aguilar, S. (2003), «Principio de precaución, políticas publicas y riesgo», Politica y Sociedad 3.

Alberini, A. et al. (2002), «Does the Value of a Statistical Life Vary with Age and Health Status? Evidence from the United States and Canaday, Discussion Paper 02-19, Resources for the Future, Washington, D.C.

Arias Maldonado, M. (2003), «Democracia y sociedad del riesgo. Deliberación, complejidad, incertidumbre», Revista de Estudios Politicos 122.

Beck. U. (1998), «Politics of Risk Society», en J. Franklin ed., The Politics of Risk Society. Cambridge: Polity Press. 9-22.

- (2001), La société du risque. Sur la voie d'une autre modernité. Paris: Aubier.

Bernstein, P. L. (1998), Against the Gods. The Remarkable History of Risk. Nueva York: Wiley \& Sons.

Boyne, R. (2003), Risk. Philadelphia: Open University Press.

Capra, F. (1983), The turning point: Science, Society, and the Rising Culture. Nueva York: Bantam Books.

Ciceron, M. T. (54 B.C.), De Re Publica. (Diversas ediciones).

Cullen, A. C. y Small, M. J. (2004), «Uncertain Risk: The Role and Limits of Quantitative Assesment», en T. McDaniels y M. J. Small eds., Risk Analysis and Society. An interdisciplinary characterization of the Field. Cambridge: Cambridge University Press. 
Cumming, R. B. (1982). «Risk and the Social Sciences», Risk Analysis 2 (2).

Denise-Lempereur, J.(2000), "Opinion publique et sécurité environnementale», La Revue international et stratégique 39.

Derby, S. L. y Keeney, R. L. (1981), «Risk Analysis: Understanding «How Safe is Safe Enough?» Risk Analysis 3.

Douglas, M. y Wildavsky, A. (1982), Risk and Culture. Berkeley: University of California Press.

Fischhoff, B. et al. (1981), Aceptable Risk. Cambridge: Cambridge University Press.

Fischhoff, B.; Slovic, P. y Lichtenstein, S. (1982), «Lay Foibles and Expert Fables in Judgements about Risk», The American Statistician 3.

Fischhoff, B. (1994), «Acceptable Risk: A Conceptual Proposal», Risk: Health, Safety \& Environment 5.

Giddens, A. (1998), «Risk Society: the Context of British Politics», en J. Franklin ed., The Politics of Risk Society. Cambridge: Polity Press.

Godard, O. (2002), «L'émergence du principe de précaution», en O. Godard et al. Traité des nouveaux risques - Précaution, Crise, Assurance. París: Gallimard.

Graham, J. D. Y Baert Wiener, J. (eds.) (1997), Risk vs. Risk. Tradeoffs in protecting health and the environment. Cambridge: Harvard University Press.

Hammitt, J. K. y Jin-Tan Liu (2004), «Effects of Disease Type and Latency on the Value of Mortality Risk,» Journal of Risk and Uncertainty 28 (1): 73-95.

Horlick-Jones, T. y De Marchi, B. (1995), «The crisis of scientific expertise in fin de siécle Europe», Science and Public Policy 22 .

Horlick-Jones, T. (2004), «Experts in risk? Do they exist? Health, Risk \& Society 2.

HSE (1996), Use of Risks Assessment Within Governmental Departments. Londres: Health and Safety Executive.

Huber, P. (1991), Galileo's Revenge: Junk Science in the Courtroom. Nueva York: Basic Books.

Kates, R. W. y Kasperson, J. X. (1983), «Comparative Risk Analysis of Technological Hazards (A Review)», Proc. Natl. Acad. Sci. USA 80.

Kelman, S. (1981), «Cost-Benefit Analysis: An Ethical Critique», Regulation 1.

Krupnick, A. et al. (2002), «Age, Healv and the Willingness to Pay for Mortality Risk Reductions: A Contingent Valuation Survey of Ontario Residents", Journal of Risk and Uncertainty 24.

Lagadec, P. (1981), La civilisation du risque. Catastrophes technologiques et responsabilité sociale. Paris: Seuil.

Lindblom, C. E. (1965), The intelligence of democracy: Decision making through mutual adjustment. New York: Free Press.

Oakeshott, M. (1991), Rationalism in Politics. Indianápolis: Liberty Fund. 
Otway, H. J., y Thomas, K. (1982), «Reflections on Risk Perception and Policy», Risk Analysis, 2 (2): 69-82.

Pareto, W. (1966), Manuel d'économie politique. Ginebra: Droz.

Perrow, C. (1999), Normal Accidents. Living with High-Risk Technologies. Princeton: Princeton University Press.

Pidgeon, N. et al. (1992), «Risk Perception», en The Royal Society comps., Risk: Analysis, Perception and Management. Report of a Royal Society Study Group. Londres: The Royal Society.

Puy, A. (1995), «Aceptabilidad social de los riesgos», Estudios de psicología 15.

Ruckelshaus, W. D. (1985), «Risk, Science, and Democracy», Issues in Science and Technology, 3.

Slovic, P. (2006), «Informing and Educating the Public about Risk», en P. Slovic, ed., The Perception of Risk. Londres: Earthscan.

Slovic, P., Fischhoff, B. y Lichtenstein, S. (1979), «Rating the Risk», Environment3.

Sunstein, C. R. (2002), Risk and Reason. Safety, Law and the Environment. Cambridge: Cambridge University Press.

Thaler, R. y Rosen, S. (1976), «The value of saving life: Evidence from the labor market», en N. Terleckyj ed., Household production and consumption. Nueva York: Columbia University Press.

Tindale, S. (1998), «Procastination and the Global Gamble», en J. Franklin ed., The Politics of Risk Society. Cambridge: Polity Press.

Tsuge, T. (2005), «A Choice Experiment Approach to the Valuation of Mortality», The Journal of Risk and Uncertainty $31: 1$.

Vanaclocha, F. J., Martinón, R. y Losada, R. (2005), «Traumatic renewal of values and value criteria in crisis management», Documentos de Trabajo Politca y Gestión 4. Madrid: Universidad Carlos III de Madrid.

Viscusi, W. K. y Joseph E. A. (2003), «The Value of A Statistical Life: A Critical Review of Market Estimates Throughout the World», Journal of Risk and Uncertainty 27: 5-76.

Woollacott, M. (1998), «Risky Business, Safety», en J. Franklin ed., The Politics of Risk Society. Cambridge: Polity Press.

Zinn, J. (2005), «The biographical approach. A better way to understand behaviour regarding health and illness?», Health, Risk and Society 7. 


\section{Artículo de Revisión}

